\title{
JOAQUIM: O PERIÓDICO QUE OUSOU TRAZER O MUNDO PARA A PROVÍNCIA
}

\author{
Daniel Verginelli Galantin* \\ Franciele do Couto Grabowski**
}

RESUMO: Neste artigo analisamos a produção textual do periódico Joaquim, publicado na década de 1940 em Curitiba. Estudamos as discussões quanto ao movimento modernista que perpassou os meios artísticos paranaenses, especialmente o grupo de intelectuais e artistas que faziam parte do periódico citado. Com isso observamos a constituição de discursos críticos aos paradigmas de arte paranense vigentes até o momento, especialmente o paranismo, em prol de uma arte que não se limite apenas a dialogar e exaltar elementos locais. Damos especial atenção à crítica a Emiliano Perneta formulada por Dalton Trevisan. A forma com que o primeiro se apropria de elementos simbolistas é criticada pelo segundo na medida em que dessa apropriação resulta uma poesia demasiadamente comportada. Tentamos assim contrapor elementos da própria poesia simbolista (Rimbaud é nosso exemplo) à forma com que Perneta formulou sua poesia. Nossa hipótese é que, em Rimbaud, há uma forte crítica à noção de identidade, a qual é mitigada na poesia criticada por Trevisan.

ABSTRACT: In this article we analysis the textual production on the Joaquim periodic, which was published in the 1940's decade in Curitiba. We research the discussions on the modernist movement which permeated the local artistic milieu, specially the group consisted on intellectuals and artists that gathered on the mentioned periodic. We can observe the constitution of critic discourses about the local established art paradigms in that moment, specially the paranism, in favor of an art model which is not limited only to the local elements. We pay special attention to the critic on Emiliano Perneta, which was formulated by the writer Dalton Trevisan. The way which Perneta appropriates elements from the symbolism is criticized by Trevisan as it results on a poesy too much conformed. So we try to oppose elements from the symbolist poetry (Arthur Rimbaud is our model) to

*Daniel é estudante de História da UFPR, bolsista de Iniciação Científica CAPES/CNPq pelo departamento de Filosofia. Atualmente estuda a obra do Marques de Sade e sua relação com o pensamento ilustrado (orientado pelo prof. Dr. José Roberto Braga Portella) e Nietzsche e as questões políticas de seu pensamento (orientado pelo prof. Dr. André de Macedo Duarte).

${ }^{* *}$ Estudante de História da UFPR. Atualmente estuda os ensaios de crítica de arte do poeta Charles Baudelaire (orientada pelo prof. Dr. José Roberto Braga Portella). 
Perneta's poetry. Our hypothesis is that in Rimbaud there's a strong critic to the notion of identity, which is mitigated in the poetry criticized by Trevisan.

\section{Introdução}

Na Europa do final do século XIX novas idéias estavam sendo consolidadas em detrimento de posturas antigas. Idéias ligadas a um esforço constante de desligamento perante as tradições das "hierarquias arbitrárias", das crenças agora tidas como "obscuras", mantendo um ideal de progresso dos conhecimentos, das técnicas e das conquistas sociais. Essas idéias não permanecem apenas no plano das idéias, assim como não restringem-se apenas à Europa. Tais idéias atravessaram o Atlântico e chegaram às Américas das mais diversas formas e muitas vezes com significativas alterações. As novas idéias apresentam ressonâncias físicas na estrutura da cidade, como, por exemplo, o petit-pavé que surgia como calçamento oficial em Curitiba trazido pela vontade de modernização e crença no progresso que, aos poucos estendia suas asas sobre a cidade. Dentro deste estado de espírito, o qual podemos denominar como “modernidade”, há um ímpeto pelo novo e, nesse sentido, várias áreas de conhecimento tomam este ideal como linha condutora. Assim, também a vida cultural e artística é tocada pelo espírito da modernidade e das vanguardas artísticas européias. Discussões acerca de um lugar da arte frente à sociedade emergente capitalista e industrial, propunham uma re-significação mais autônoma para os artistas e suas criações, como também reivindicar rupturas com regras clássicas tradicionais ${ }^{1}$. O contato com este cenário internacional deu-

${ }^{1}$ Apesar de afirmarmos uma ruptura dentro do ambiente artístico no final do século
XIX, ressaltamos a diversidade de manifestações culturais existentes antes mesmo
desse período que, sob um ponto de vista podem ser consideradas como crítica à
postura artística tradicional. Nas artes plásticas caricaturas e gravuras, por exemplo,
eram amplamente difundidas. Essas, entretanto, escapavam das regras e valores
tidos como ideais, mas, se direcionavam a reflexões críticas políticas e sociais, e 
se uma vez que muitos artistas nacionais e paranaenses receberam apoio financeiro do Estado para realizarem seus estudos na Europa. Nota-se, por exemplo, a influência do simbolismo, trazido da França e da Bélgica principalmente por paranaenses no final do XIX. Neste último caso, cabe acrescentar que as pessoas que tiveram contato com tais manifestações artísticas não deixaram de adaptar as idéias do movimento para que entrassem em confluência com as da elite local, a qual buscava a construção de uma identidade regional, uma vez que o Paraná havia se emancipado de São Paulo em 1853. Era então necessário construir sua especificidade regional, sua identidade que agora definiria o que é ser paranaense. Com isso, houve uma mistura (de gosto duvidoso) de simbolismo, positivismo, cientificismo e até indianismo romântico (CAMARGO, 2007, p. 71). Aqui já percebemos uma especificidade quanto ao modernismo nacional pois, quando algum membro da Joaquim critica o foco no regionalismo e a exaltação de uma pretensa identidade local paranaense (tudo isso em prol de uma maior abertura às questões que agora circulavam pelo mundo, e não pela rua XV de Novembro), o que é criticado não é especificamente a tradição. Como será apontado posteriormente, não havia uma tradição local nas artes, ao menos não tão forte quanto havia na Europa; a tradição local criticada poderia até mesmo ser colocada como moderna, mas não modernista. Ainda acreditamos ser necessário destacar, que as fontes analisadas foram produzidas num outro momento da modernidade nacional, aquele da primeira metade do XX. Normalmente quando os joaquinistas criticam a tradição, esta geralmente é formada pelos artistas do final do XIX.

O fenômeno da modernidade apresenta íntima ligação com o elemento urbano (GRUNER; SEREZA, 2009, p.149), ou seja, só podemos pensar em modernidade e modernismo no contexto urbano. Mesmo no caso de Curitiba, que não era exatamente um grande centro, as idéias modernas chegaram já no século XIX, e encontramos

não abertamente a reflexão sobre conservadorismo artístico. Além disso, havia uma hierarquia de gênero e temas. A relevância da ruptura que propomos ocorreu por parte de artistas dentro das artes "maiores”, sobretudo a pintura. 
sua intensificação na primeira metade do XX, momento constitutivo da experiência dos artistas que escreviam na Joaquim. Cabe ressaltar que, nesse momento (anos 40 do século XX), Curitiba abrigava aproximadamente 127.000 habitantes $^{2}$ e já haviam planos de urbanização. O maior exemplo desse caso para a época é o Plano Agache, colocado em prática entre 1941 e 1943. Nada mais dentro da idéia de modernidade uma vez que "símbolo da vitória da técnica e da ciência, ela é, além da realização de um projeto racional, espaço de construção de uma utopia cuja síntese seja, talvez, as pretensões de ordenação espacial e a busca da higiene - tanto física quanto moral que perpassam os discursos e as práticas dos planejadores urbanos” (GRUNER; SEREZA, 2009, p.149).

Cabe ressaltar que a modernidade está intimamente relacionada com a literatura e o mercado editorial, uma vez que estes elementos têm como palco o ambiente urbano. É somente no ambiente urbano que se configuram uma série de lugares e instituições que possibilitam a produção e circulação de idéias (universidades, bibliotecas, cafés, teatros, cinemas, museus, revistas, dentre outros) constituintes das discussões literárias, filosóficas e estéticas. Assim há espaço para a experimentação, discussão e criação de novos discursos que abrangem todos esses domínios (estético, literário, filosófico, etc.). Nesse grande contexto, dentro da experiência urbana moderna e, mais especificamente, em diálogo com as idéias modernistas, que estão inseridos aqueles que escreveram na revista Joaquim, mas também aqueles que os joaquinistas criticavam.

Em meio a este cenário e considerando o contexto paranaense do final do XIX e início do XX, podemos dizer que as artes mantiveram-se ligadas à tradição moderna da Academia. Na pintura, por exemplo, predominavam os temas históricos e de paisagem, mesmo após todas as discussões surgidas com a Semana de Arte Moderna. Nesta leva, o movimento Paranista surge buscando uma

${ }^{2}$ Dados obtidos no site da Casa da Memória, Fundação Cultural de Curitiba. http://www.casadamemoria.org.br/index_historiadecuritiba.html, acessado em 26/04/2010. 
identidade regional e baseando-se em uma iconografia que tentava ressaltar elementos da flora paranaense, com tendência a estilizá-los a fim de obter imagens - através de figuras como pinhão, erva-mate e a araucária - as quais acabavam por corresponder com as idéias da elite ervateira que, no Paraná, possuía considerável poder político e econômico. Um dos principais artistas paranistas, o escultor João Turim, depois de seu retorno da Europa permanece em Curitiba onde realiza uma série de monumentos e obras particulares. Dentre estas são notáveis as obras feitas para o Clube Curitibano, suas decorações e projetos arquitetônicos, assim como sua casa e atelier. Estes são ótimos exemplos da relação iconográfica de sua obra com as tendências decorativas, provavelmente aprendidas em sua estadia na Bélgica. Estas tendências combinavam elementos da modernidade, do ecletismo fin-de-siècle, do art-déco e de uma estilização típica da moderna arquitetura fascista, com suas fachadas e elementos decorativos baseados nas formas clássicas monumentais (CAMARGO, 2007).

\section{Um periódico anti-provinciano}

Os membros da revista Joaquim (1946-1948) partilhavam de outra concepção de arte (em suas relações com a sociedade e suas manifestações culturais) que não aquela da Academia. Mas era justamente uma concepção acadêmica que vigorava no espaço artístico paranaense. Editada pelo artista plástico Poty Lazzaroto e o contista Dalton Trevisan, a revista pretendia derrubar idéias antigas e educar o gosto dos leitores. Sua proposta foi a de estabelecer um diálogo entre as idéias artísticas nacionais e internacionais trazendo juntamente com estas, questões políticas e sociais a fim de reposicionar a produção artística na e para a sociedade paranaense, ampliadas sob perspectiva nacional e mundial. Tal objetivo se faz através da postura dos autores curitibanos que procuravam manter relações com intelectuais e artistas nacionais e internacionais, permitindo que os mesmos publicassem artigos na Revista - inclusive 
traduzindo poesias e trechos literários -, abrindo espaço para debates e discordâncias, o que anima ainda mais a leitura e proporciona maior conhecimento das discussões correntes.

A definição dos membros da Joaquim como modernistas nos remete, para algumas peculiaridades do âmbito artístico. Como o meio artístico acadêmico francês de boa parte dos séculos XVIII e XIX, no Paraná da segunda metade do século XX predominou a dependência estatal. $\mathrm{O}$ governo francês patrocinava os Salões de Belas Artes que eram a maior instância de consagração dos artistas. Dessa forma, a arte tida como oficial era a acadêmica.

Os artistas locais se esforçam para conquistar a aceitação oficial uma vez que o sistema de comércio de obras, o qual permitiria a subsistência artística, inicialmente restringe-se às diretrizes propostas pela elite paranaense. A sociedade tende a considerar que a cultura é de responsabilidade do Estado, ao mesmo tempo que este utiliza desses meios para difusão e propaganda de idéias. A arte paranaense da segunda metade do século $\mathrm{XX}$ não se alinha ao estilo acadêmico, mas pretende se alinhar à arte moderna dos importantes circuitos internacionais. Enquanto na França os salões foram extintos porque eram instâncias que não se prestavam ao reconhecimento da arte moderna, no Paraná eles foram a porta de entrada dessa nova vertente. Aqui, a inserção da arte moderna se deu dentro das instituições estatais.

\section{Noções e discussões sobre poesia, arte e engajamento em Joaquim}

Os textos publicados na revista Joaquim ampliam as discussões sobre arte, englobando literatura, artes plásticas, música; bem como relacionam tendências artísticas a contrapontos de teorias filosóficas e acontecimentos contemporâneos. As soluções e pontos de vista, entretanto, divergem em pontos mais específicos.

No artigo publicado na edição número 4 , em setembro de 1946, o escritor Temístocles Linhares analisa a tarefa da poesia na contemporaneidade, sua função. Reivindica ao poeta (sem especificar 
exatamente qual poeta, dando a entender que se refere ao "tipo" poeta), através da poesia, a salvação do homem diante de um "mundo sem sentido, uma vida sem finalidade e sem razão de ser". Neste artigo, intitulado "Salvação pela poesia", Linhares menciona que mesmo que esta salvação possa parecer absurda, somente o poeta conseguiria destruir o orgulho de nossa razão, pois a própria vida não passa de um absurdo onde não há justificativa para a existência. Sendo assim, considera como menor o trabalho do filósofo e do romancista pois estes seriam guiados pelo ordenamento do mundo através do uso da razão.

Uma vez que a realidade encontrar-se-ia dominada pela falta de sentido, angústia, absurdo, reduzida pela intencionalidade fenomenológica $^{3}$, a vida - em toda a sua potencialidade - somente conseguiria ser transfigurada através da poesia, por esta se tratar de uma nova linguagem que se manifesta através do absurdo. Além da poesia, Linhares defendeu também uma missão ao poeta:

Ao poeta, como é da sua missão, coube viver e sentir, antes dos outros, esta vida moderna, no que ela trazia de mais complexo e profundo para a

${ }^{3}$ A noção de intencionalidade fenomenológica nada mais é que a intencionalidade da consciência formulada pelo filósofo Edmund G. A. Husserl e retomada por diversos fenomenólogos e existencialistas, dentre os quais destacamos Jean-Paul Sartre. Em "Uma idéia fundamental da fenomenologia de Husserl: a intencionalidade", Sartre coloca a intencionalidade como relacionamento da consciência com o mundo de forma radicalmente diferente das teses idealistas (que reduz o mundo à consciência) e da epistemologia (que reduz a consciência ao conhecimento). A intencionalidade basicamente coloca que "conhecer é 'explodir em direção a', desvencilhar-se da úmida intimidade gástrica para fugir, ao longe, para além de si, em direção ao que não é si mesmo, para perto da árvore e no entanto fora dela, pois ela me escapa e me rechaça e não posso me perder nela assim como ela não pode se diluir em mim: fora dela, fora de mim" (SARTRE, 2005, p. 56). Dessa forma, toda consciência é transcendência, fuga do interior (a consciência ela mesma não tem interior). Neste escrito de 1939, Sartre ainda relembra a célebre fórmula "toda consciência é consciência de alguma coisa", colocando-nos mais uma vez que "essa necessidade da consciência existir como consciência de outra coisa que não ela mesma, Husserl chama de intencionalidade" (SARTRE, 2005, p. 57). 
sua revolução. Mas enquanto os poetas sentem e interpretam assim o nosso drama, nós não os compreendemos porque não tomamos ainda consciência da nossa própria realidade e da realidade revolucionária do mundo moderno (LINHARES, 1946, p. 12)

Esse viés quase emancipatório para a poesia parece não levar em consideração as diferenças entre os movimentos e grupos. Isso porque Linhares afirma que haveria um processo anterior, mas intrínseco à estética poética, tornando todas as poesias um meio de libertação do espírito, condução às fontes puras da vida e um processo individual de voltar-se para si. Dessa forma, o poeta não possuiria uma natureza humana superior à qualquer outro cidadão, pois qualquer indivíduo teria em sua essência como alcançar este processo anterior. Assim, todos poderiam se utilizar de imagens poéticas para penetrar o mundo, o qual não deveria ser explicado, mas vivido. Linhares, entretanto, não esclarece esse "pensar poeticamente", afirmando a todo o momento a figura do poeta como aquele que melhor compreende as contradições da vida.

Ainda que o autor admita ser a poesia uma linguagem do absurdo, Linhares não rompe com a compreensão do mundo. Ela ocorreria a partir de um regresso diante da tomada de consciência do absurdo e da ilogicidade das coisas: num retorno ao passado, à infância, à um tempo perdido, afim de buscar fontes mais puras (originárias) do seu presente, num movimento de fuga dos quadros fechados que estrangulam, e rumo à libertação e salvação através do absurdo poético.

Não obstante, o fato de Linhares ter legado à poesia a possibilidade de lucidez frente à vida humana afirma aspectos problemáticos: tende a considerar a poesia lugar de reflexo da vida, cuja posse do mundo pelo poeta lhe confere a capacidade de desvelamento; e considera a poesia, assim como o mundo, o lugar da desordem e da irracionalidade, por mais que não tenha utilizado propriamente estes termos.

Em outros artigos publicados na revista nota-se uma confluência de idéias que defendem um papel ativo do intelectual 
dentro da sociedade, marcada por uma vida absurda e paradoxal. Ainda na edição número 4, em Filosofia e arte, Erasmo Pilotto propôe uma discussão a fim de desvencilhar a poesia do convencional e dos valores morais, no intuito de "atingir a um ponto de vista em que as coisas the aparecessem em sua plena luz e em suas faces verdadeiras" (PILOTTO, 1946, p. 6). No texto Pilotto inicia a discussão utilizando os argumentos de Jean-Paul Sartre quanto à necessidade de dissolução da ingenuidade pelo poeta. Diferente de Linhares, afirma que a arte deve ser "de um lado capaz de refletir a sua emancipação em face da Vontade, e, de outro, criada na atmosfera da maior consciência, dentro de uma estética que se tenha elaborado em função dessa consciência, ou libertação ou filosofia" (Pilotto, 1946, p.6). Pilotto ainda cita o artigo mencionado anteriormente neste trabalho, Salvação pela poesia, de Temístocles Linhares, e a tendência nietzcheana ${ }^{5}$ do autor. Enquanto Linhares rejeita uma reflexão que englobe a filosofia por esta se restringir à racionalidade, Pilotto acentua a importância da análise crítica, com destaque para a reflexão de categorias e implicações a partir da

4 No artigo Erasmo Pilotto detalhou as categorias de vontade e malícia, provavelmente de acordo com o autor Jean-Paul Sartre e Schopenhauer, embora não deixe evidente isso no texto uma vez que somente citou o autor após ter trabalhado os conceitos e as significações implícitas dos mesmos na conduta artística. Vale notar como os textos de autores estrangeiros eram conhecidos, mesmo que apropriados segundo uma leitura que distorcia teorias, para encaixar adequadamente a defesa de alguma postura.

${ }^{5}$ Neste ponto acreditamos que é melhor deixar claro que o ponto de vista de Linhares não é estritamente nietzschiano. Temas como a irracionalidade do mundo e a arte (não necessariamente a poesia) como possibilidade de criação de sentido e justificação estética da existência, são parte da filosofia de Nietzsche. No entanto os escritos de Linhares deixam evidentes uma aproximação muito maior com a fenomenologia e o existencialismo que com Nietzsche. Basta atentarmos para o fato de Nietzsche negar qualquer "origem" transcendental da arte nos termos propostos por Linhares, assim como apontar para a possibilidade de a arte ser expressão e lugar de manifestação do "ideal ascético". Este não é momento para aprofundarmos tais pontos, no entanto, basta a indicação da leitura das obras $O$ nascimento da tragédia; Genealogia da Moral (especialmente a terceira dissertação); e Crepúsculo dos Ídolos. 
filosofia. Se trataria de tornar a poesia consciente e não desvinculada da razão. No entanto, o autor considera a intencionalidade da natureza consciente, "toda consciência é consciência de alguma coisa", (PILOTTO, 1946, p. 6).

Antônio Cândido, por sua vez, discute sobre um possível dever da intelectualidade, no artigo Plataforma da nova geração, publicado na edição $\mathrm{n}^{\circ}$ 9. Diferente de Linhares e Pilotto para quem a poesia se apresenta quase como a via de esclarecimento e emancipação do homem e da vida, Cândido procura argumentar que o dever se estende a todo cidadão, cabendo a cada um utilizar suas armas no intuito de desempenhar a sua tarefa social. Segundo o autor, "a nossa tarefa máxima deveria ser o combate a todas as formas de pensamento reacionário" (CÂNDIDO, 1946, p. 6), inviabilizando uma ação direta ao escritor.

O único receio de Cândido quanto ao intelectual seria sua limitação ao campo teórico, ao preconizar a busca de soluções para os problemas filosóficos e agonísticos do homem e se afastar das situações imediatas do mundo. Dessa forma, ele afirma que a tarefa do intelectual, por mais distinta da tarefa dos demais cidadãos, deve ser útil para o "nosso" tempo":

Do mêdo que nos toma a todos de estarmos sendo inferiores à nossa tarefa; ou de não conseguirmos fazer algo de definitivamente útil para o nosso tempo, como, de um modo ou de outro, fizeram os rapazes de Vinte. Você tem algum critério para afastar êsse mêdo? Eu não posso bem dizer que tenha, mas confesso que êsse combate a tôdas as formas de Reação, que eu

\footnotetext{
${ }^{6}$ Novamente a famosa fórmula já explicada anteriormente.

${ }^{7}$ Após o final do artigo de Antônio Cândido, há uma nota, separada, mencionando outras revistas de "novos"/"moços" que circulam no país. São elas: Paralelos, em São Paulo; Agora, em Goiás; e Uirapurú, em Santa Catarina. Acreditamos que para uma análise mais ampla e comparativa das discussões sobre arte durante a década de 1940, a citação dessas possa ser útil.
} 
apenas sugeri, nos ajudaria muito a ficar livres dêle ${ }^{8}$ (CÂNDIDO, 1946, p. $6)$.

Ao comparar Linhares, Pilotto e Cândido, nota-se dois pontos em comum: o dever de ater-se à época para produzir algo mais profícuo - por mais divergentes que sejam as propostas -; e a internacionalização das discussões acerca da literatura e das artes plásticas. A frase de Stendhal, já citada neste trabalho, é constantemente retomada para servir como princípio para os novos artistas.

\section{O caso Emiliano}

Como podemos perceber, mesmo no interior da própria revista Joaquim havia uma multiplicidade e divergência de idéias que muitas vezes percorriam diferentes caminhos. Uma das divergências que pretendemos destacar no presente trabalho refere-se à valorização da poesia simbolista no Paraná. Com a análise desta divergência procuramos entender melhor as posições adotadas pelos membros da revista assim como aqueles com os quais eles discutiam. De antemão ressaltamos não tratar-se de uma discussão direta entre dois articulistas (Dalton Trevisan e Temístocles Linhares serão o exemplo), mas sim das avaliações divergentes de ambos.

Na revista de número 2, de junho de 1946, Dalton Trevisan faz uma avaliação crítica da obra do poeta paranaense Emiliano Perneta, mostrando sua acidez já no título do artigo: "Emiliano Perneta, poeta medíocre”. Trevisan faz uma análise focando-se na obra do poeta e coloca em segundo plano (mas não de lado) sua vida; afirma que Emiliano foi um poeta vítima da província "e se, por isso, só não o compreendemos, como até o amamos em sendo prata de casa, devemos contudo julgá-lo pela sua obra, sem ter conhecido o

\footnotetext{
${ }^{8}$ Essas sugestões, citadas no final do texto, discutidas durante o artigo pelo autor. Ele as apresentou como tendências muito fecundas, mas perigosas; são elas: filosofias idealistas, sociologia cultural e literatura personalista.
} 
homem, que foi mais brilhante do que o artista" (TREVISAN, 1946, p. 16). Aqui podemos perceber um esforço da parte de Trevisan em avaliar a obra do autor a partir dela mesma e em comparação com outros poetas, de certa forma ainda procurando afastar-se da valorização quase incondicional da arte local, estabelecida pelo paranismo. O momento e a geração a partir de onde Trevisan fala, é colocado por ele mesmo:

Não é em vão que a nossa geração, com sua mentalidade formada entre o suor, o sangue e as lágrimas de duas guerras mundiais, sofrendo a sua inquietude tremenda, a provar experiências decisivas na própria carne, procedeu como um motivo de sobrevivência a subversão de todos os valores. Nossa geração não quer mais nutrir-se dos equívocos que a afastem da rua dos homens.

Um destes equívocos é a mística de Emiliano. Ele faz uma poesia de casinha de chocolate, desligada da vida, onde não há lugar para as asas do pássaro, o grito de um humano amor, o riso de uma criança ao sol, o sonho de saúde de um moço convalescente (TREVISAN, 1946, p. 16).

Ou seja, Trevisan está apontando que a poesia de Perneta está desligada do mundo, ou quer-se desligar do mundo, posição que está nos antípodas da geração que faz parte de Joaquim.

O artigo ainda apresenta uma rápida recapitulação do percurso artístico de Perneta, que passou pelo romantismo e parnasianismo antes de incorporar o simbolismo. Mesmo aqui surgem as ácidas críticas, onde, comparado com Olavo Bilac ou Emílio de Menezes, Perneta dista tanto "quanto o canto do vira-bosta dista do canto do sabiá” (TREVISAN, 1946, p. 16). Para Trevisan, tanto em sua forma quanto em seu conteúdo, a poesia de Perneta é comportada:

Emiliano fez poesia, como se fez poesia naquele tempo, afim de ser recitada nas sessões lítero-musicais dos colégios em festa do dia da árvore. E, precisamente, sua poesia, borrifada em água de flor, é uma POESIA DE DIA DA ÁRVORE. Versos bonitos, com sonoridade e sílabas de encher bochechas, mas por acaso poesia é mais do que isso? Se é, Emiliano não foi poeta (TREVISAN, 1946, p. 16). 
Segundo Dalton, apenas o nome de Cruz e Souza seria uma contribuição significativa do simbolismo no Brasil. Ainda segundo Trevisan, Perneta escreveu partindo de um ponto pessoal mais que artístico, sendo esse plano pessoal perpassado por um ódio à vida.

No plano da obra propriamente dita, a construção poética de Emiliano Perneta é resumida a partir de uma estratégia de "transportar para nossa língua um figurino de escola, sem nada lhe dar de contribuição pessoal, antes cortando mal as mangas e errando nas medidas de um terno talhado pelos franceses" (TREVISAN, 1946, p. 16). Tudo isso ainda acompanhado de "indefectíveis imagens de dicionário grego-latino, como filhinhas bem comportadinhas que vão à missa com a titia" (TREVISAN, 1946, p. 16). O autor de $O$ vampiro de Curitiba deixa alguns pequenos elogios quanto à pessoa de Perneta, colocando que

se era poeta mau, Emiliano foi também uma pessoa encantadora, com uma personalidade imponente, conversador mágico, bom amigo. Para a Curitiba colonial de então, com seus ares de príncipe no exílio, seu cachimbo de Flaubert, a blusa de veludo de Baudelaire, o colete vermelho de Gautier, ele - mais do que qualquer um - era o ar de Paris, Paris, o ledor do Mercure de France, o boêmio que escandalizou os pais de família - uma grande promessa, enfim! (TREVISAN, 1946, p.16).

Pelo que percebemos, as críticas de Trevisan não são dirigidas ao simbolismo propriamente, mas ao modo com que Perneta se apropriou do mesmo; uma aproximação fadada ao fracasso tentaremos mostrar o motivo no decorrer do trabalho. Seu lirismo permanece

Sempre a casinha de chocolate, e compre que se digam tais coisas, afim de que os moços, em vez de trilhar seu caminho fechado, tomem as estradas alegradas de Sol de um Baudelaire ou um Verlaine ou um Vinícius de Morais. Me entendam bem os chauvinistas. Porque, em arte, não há prata da casa, é-se Dostoiéviski ou L. Romanowski, é-se Rimbaud ou ................, e pobre de quem lê 'Ciume da Morte', em vez de Doistoiwski (sic), por causa de que um é comunista russo e, o outro, nasceu em Mal. Mallet... E, pois, hélas! Não se perca tempo, vamos aos valores supremos, a essas 
experiências decisivas de Rilke, Aragon, Drummond de Andrade. 'Ilusão' é, porventura o melhor livro de poesia escrito no Paraná, grato ao nosso coração por um laço afetivo, mas nem por isso é livro que ultrapasse as fronteiras da rua 15, e, para nós, neste instante, são as fronteiras do mundo, e não as da rua 15, que procuramos atingir (TREVISAN, 1946, p. 17).

Assim termina o artigo de Trevisan, onde podemos notar a explosão de vida e revolta contra o provincianismo paranaense, que caracterizou a geração de 40 e, mais especificamente, aqueles que faziam parte de Joaquim. Ao fim parece que somos levados ao tema de fundação da revista; novamente a frase de Stendhal.

Nos antípodas da avaliação de Dalton Trevisan podemos apontar o artigo de Temístocles Linhares no número 6, datado de agosto de 1946 e intitulado de Raízes do simbolismo no Paraná. Segundo este autor, o simbolismo paranaense "não se apresentou apenas como um simples reflexo, uma moda literária passageira, com caracteres postiços e sem raízes na terra” (LINHARES, 1946, p. 5). Embora seja difícil provar que tal artigo tenha sido uma reposta ao de Dalton Trevisan, uma vez que não houve tréplica do mesmo nos números posteriores, e seu nome sequer tenha sido citado no artigo de Linhares, a divergência de posições salta-nos aos olhos. Segundo Linhares o simbolismo é um estilo proveniente do norte da Europa (mesmo na França os simbolistas proviriam da região norte) mesclado a uma filosofia mediterrânica, a platônica. Teria sido justamente essa combinação "ou então o decadentismo dos franceses, em que sobressaía a figura daquela criança grande que foi Verlaine e que constituiu uma das admirações de nosso Emiliano” (LINHARES, 1946, p. 5). Ou seja, os nomes de Perneta e Paul Verlaine são colocados lado a lado, desfazendo implicitamente a crítica de Trevisan.

A abordagem de Linhares chega a associar o simbolismo com a natureza paranaense:

Chegaremos ao ponto em que desejaríamos ficar, defendendo a tese de que o simbolismo no Paraná teve feições características e bem concordantes com a sua psicologia social, assim como com a paisagem tantas vezes 
européia que nos circunda e que nos levava naqueles tempos, bem como sucedia com os europeus, à prática dessa nova forma de poesia, que não era descritiva, mas que antes procurava mais sugerir do que descrever (LINHARES, 1946, p. 6).

Aqui podemos até pensar se o autor não acaba por trazer uma noção de identidade paranaense que teria, como uma de suas manifestações, o simbolismo. Ao menos a associação dos elementos naturais do Paraná e da Europa manifesta-se explicitamente. A intuição confirma-se logo em seguida, quando Linhares infere que

o nosso estado de espírito, aquilo que nos era já constitucionalmente próprio, em nossos começos de vida regional, encontrava no simbolismo, não apenas no simbolismo estético, mas também no simbolismo ético e filosófico, sem falar no geográfico em tantos aspectos igual ao europeu, uma forma de expressão original, que nos permitia afirmar o nosso ser, muito mais voltado para o mundo de nossa representação do que para as realidades da vida exterior (LINHARES, 1946, p. 5).

Oras, o “estado de espírito” que é “constitucionalmente próprio" do paranaense e do Paraná, aquilo que afirma o seu "ser” pode muito bem ser tratado como sua identidade. Assim, o Paraná traria em si uma espécie de “espírito” onde o simbolismo era já uma potencialidade ligada à “psicologia social” de seu povo em uma terra tão semelhante à européia.

Linhares deixa claro que o simbolismo seria um fenômeno de repercussão universal de forma semelhante ao romantismo, "mais um estado de espírito do que propriamente uma estética, não atentamos para a desigualdade de condições sociológicas e históricas” (LINHARES, 1946, p. 5). No caso paranaense o autor destaca a formação da população a partir de "um caldeamento muito maior que qualquer outro brasileiro em matéria de raças (...)” (LINHARES, 1946, p. 5), o que resultou numa timidez e profundidade psicológica enorme que fazem do paranaense "um cultivador de interioridades mais requintado que qualquer outro irmão seu da Federação" (LINHARES, 1946, p. 5). Aqui Linhares traça um perfil psicológico do "paranaense em geral” que nos faz criar praticamente uma imagem 
dostoiéviskiana semelhante àquela de Notas do subterrâneo. Assim parece-nos que o autor acaba traindo o que ele mesmo disse, pois estaria trazendo como fator explicativo, justamente elementos históricos e sociológicos, por mais problemáticos que estes sejam ${ }^{9}$. Todas essas características ainda colocariam que "o paranaense está bem mais próximo do mineiro do que do paulista ou do catarinense" (LINHARES, 1946, p. 5).

O autor admite que esta poesia está ao alcance apenas de uma elite, mas que satisfazia a necessidade do "profundo processo de encontro consigo mesmo em que se debatia o homem de inteligência e sensibilidade do Paraná" (LINHARES, 1946, p. 5) numa época (a saber, o fim do XIX, quando Perneta escrevia) onde o princípio de identidade poderia se dissolver a qualquer momento.

\section{Identidade e simbolismo}

Mas é exatamente esse princípio que nos parece estar dentre as críticas de Trevisan à Perneta. Nada mais retrógrado que afirmar a identidade justamente numa época onde, a partir das experiências mundiais, viu-se que esta formava-se a partir da exclusão da diferença; e isso a partir de um veio literário que dedicou-se especialmente a essa crítica. Talvez esse seja um dos elementos que Dalton Trevisan caracteriza como "comportado" na poesia de Emiliano Perneta. Michel Collot nos chama a atenção para o jogo entre identidade e alteridade presentes na poesia simbolista, a qual irá influenciar profundamente as vanguardas do XX como no caso do poeta Guillaume Apollinaire, que por sinal teve trabalhos seus publicados na Joaquim. Segundo Collot, que adota a ontologia heideggeriana na elaboração de seu estudo, "é o encontro do que escapa aos códigos estabelecidos, a confrontação com o Outro da

\footnotetext{
${ }^{9}$ Aqui pensamos ser necessário destacar que ainda não há indícios que Linhares compartilhe totalmente com o pensamento de que o Paraná seria fundamentalmente branco e europeu, relação identitária que causou, e ainda causa inúmeros problemas sociais no Estado e que de certa forma está relacionada ao movimento paranista.
} 
linguagem, que leva o poeta a reinventar a língua, a fazer ouvir, com a mesma língua, uma outra palavra” (COLLOT, 2006, p.30). A modernidade teria, nesse sentido, trazido a experiência da alteridade do domínio da transcendência para o cotidiano: "a seus olhos é nosso mundo e o próprio Eu que se revelam outros” (COLLOT, 2006, p.30). Aqui o autor usa Baudelaire como o exemplo maior dessa transferência.

Vejamos também como a identidade manifesta-se em alguns trechos de Une saison en enfer, mais especificamente no trecho intitulado Mauvais Sang (Mau Sangue) de Arthur Rimbaud, considerado um dos maiores simbolistas:

J'ai des mes ancêtres gaulois l'oil bleu blanc, la cervelle étroite, et la maladresse dans la lutte. Je trouve mon habillement aussi barbare que le leur. Mais je ne beurre pas ma chevelure.

Les Gaulois étaient les écorcheurs de bêtes, les brûleurs d'herbes les plus ineptes de leur temps (RIMBAUD, 2008, p. 20) ${ }^{10}$.

Mais à frente, a identificação com os campos mais marginais da identidade européia acentua-se:

Si j'avais des antécédents à un point quelconque de l'histoire de France! Mais non, rien.

Il m'est bien evident qui j'ai toujours été race inférieure. Je ne puis comprendre la revolte. Ma race ne se souleva jamais que pour piller: tels les loups à la bête qu'ils n'ont pas touée (RIMBAUD, 2008, p. 22) ${ }^{11}$.

${ }^{10}$ Como utilizamos a versão bilíngüe, segue a tradução proposta:

“Tenho dos ancestrais gauleses olhos azuis-claros, crânio estreito, imperícia na luta. Minha vestimenta acho tão bárbara quanto a deles, mas não emplastro o cabelo.

Os gauleses eram os carneadores de animais e queimadores de campo mais ineptos da época” (RIMBAUD, 2008, p.21).

${ }^{11}$ “Se eu tivesse antecessores a uma altura qualquer da história da França! Mas não, nada.

Fica evidente que fui sempre da raça inferior. Não posso compreender a revolta. Minha raça só se subleva para pilhar, como os lobos com o animal que não mataram" (RIMBAUD, 2008, p.23). 
Justamente quando a França procurava identificar-se com o império romano, Rimbaud, que escreveu esta obra entre 1870 e 1873, identifica-se com os gauleses, vistos como bárbaros atrasados; quando os discursos racialistas estavam surgindo e afirmando a superioridade branca européia, Rimbaud diz que pertence à raça inferior. Encontramos então uma relação com a identidade radicalmente diferente daquela apontada por Linhares. Digamos que, se Linhares está usando o simbolismo como movimento constitutivo da identidade paranaense, Rimbaud faz de sua poesia o lugar de dissolução da identidade unitária. No campo lingüístico e filosófico se passa algo muito semelhante: "Ele [Rimbaud] rejeita a concepção cartesiana que dá ao sujeito a faculdade de coincidir consigo mesmo no ato de pensar: 'Está errado dizer: Eu penso. Deveríamos dizer: Pensam-me’” (COLLOT, 2006, p. 36). Essa dissolução do princípio de identidade parece resumir-se num trecho da correspondência entre Rimbaud e Georges Izambard EU é um outro. Azar da madeira que se descobre violino” (RIMBAUD apud COLLET, 2006, p. 36).

O artigo de Dalton Trevisan não faz essa análise da relação entre identidade e alteridade na obra de Perneta, mas podemos dizer que a ausência dessa contestação seja um dos elementos que fazem com que a poesia de Perneta soe tão comportada aos olhos de Trevisan. Da mesma forma, ser simbolista no Paraná do fim do XIX, ter acesso a essa manifestação cultural através do contato com a literatura francesa apresenta-se como uma experiência totalmente diversa; era necessário ter uma posição relativamente estável nas camadas da elite. Os contextos são radicalmente diferentes uma vez que Rimbaud escreveu ainda nos ecos dos movimentos de 1848 quando ainda ressoavam ecos do pessimismo soberano dos autores que presenciaram tanto o momento de concretização de um sonho, com a derrubada do governo de Luís Filipe em fevereiro, quanto o seu esfacelamento, em julho, com as medidas tomadas pelo governo para reprimir os que simpatizavam com idéias de esquerda. Através 
da leitura proposta por Dolph Oehler ${ }^{12}$, achamos possível inferir a possibilidade de haver uma permanência deste pessimismo trinta anos depois, com a derrota francesa na guerra contra a Prússia. Um dos fatores que influenciaram o pessimismo da geração dos anos 70 do XIX. Por fim ainda acrescentamos a traumática experiência da Comuna de Paris em 1871 a qual está presente diretamente nos poemas Chant de guerre parisien, Les mains de Jeanne-Marie e Paris se repeuple (nossa sugestão de tradução dos títulos é Canto de guerra parisiense, As mãos de Jeanne-Marie e Paris repovoa-se, respectivamente).

Parece-nos que não seria cabível cobrar a vivência de experiências como estas para se fazer poesia simbolista. Mas novamente, a poesia de Linhares é "comportada" para Trevisan não devido ao fato de o primeiro não ter vivenciado momentos revolucionários, mas porque ela rendeu-se ao gosto e aos desejos das elites paranaenses, acabando, de certa forma, por institucionalizar sua arte.

\section{Em vias de conclusão}

Percebemos que haviam significativas diferenças sobre determinados assuntos entre os autores da revista Joaquim (a saber o valor dos elementos locais na arte, o papel da arte e os critérios com os quais ela é avaliada). No entanto, o intuito preconizado pelos editores seria a recusa de uma arte paranaense cujo objetivo fosse respaldar a emancipação do Estado, dando-lhe ares de uma terra e gente que possuía identidade própria. Seu alvo eram as ressonâncias do movimento paranista, no qual os artistas, além de manterem regras acadêmicas conservadoras, tratavam a arte como uma conseqüência do "ser" paranaense, tornado causa artística, além de reduzirem a arte à expressão e coroação de qualquer elemento local.

12 OEHLER, Dolph. O Velho Mundo desce aos Infernos: auto-análise da modernidade após o trauma de junho de 1848 em Paris. São Paulo, Companhia das Letras, 1999. 
Para Dalton Trevisan, e para outros paranaenses que escreveram na Joaquim, esse ethos não apenas representava um idealismo infundado, mas prejudicava a circulação de obras de literatos e de artistas plásticos que difundiam idéias diferentes dos cânones clássicos do movimento, cânones que já estavam mais do que hora de serem questionados no caso paranaense.

\section{FONTES: REVISTAS}

Revista Joaquim, Curitiba, julho de 1946, $\mathrm{n}^{\circ} 2$.

Dalton Trevisan, "Emiliano Perneta, poeta medíocre”

Revista Joaquim, Curitiba, julho de 1946, $\mathrm{n}^{\circ} 4$.

Temístocles Linhares, "Salvação pela poesia"; Erasmo Pilotto, "Filosofia e arte"

Revista Joaquim, Curitiba, julho de $1946, \mathrm{n}^{\circ} 6$.

Temístocles Linhares, "Raízes do simbolismo no Paraná”

Revista Joaquim, Curitiba dezembro de 1946, n9.

Antônio Cândido, "Plataforma da nova geração"; Guido Viaro, “A geração dos vinte anos na ilha”

\section{BIBLIOGRAFIA}

CAMARGO, Geraldo Leão Veiga de. Paranismo: arte, ideologia e relações sociais no Paraná. 1853-1953. Tese (doutorado em História). Setor de Ciências Humanas, Letras e Artes. Universidade Federal do Paraná, Curitiba, 2007.

COLLOT, Michel. O outro no mesmo. Alea, Rio de Janeiro, v. 8, n. 1, pp. 29-38, jan./jun. 2006. 
FRIEDRICH, Hugo. Estrutura da Lírica Moderna. São Paulo, Duas Cidades. 1991.

OEHLER, Dolph. O Velho Mundo desce aos Infernos: auto-análise da modernidade após o trauma de junho de 1848 em Paris. São Paulo, Companhia das Letras, 1999.

RAYMOND, Marcel. De Baudelaire ao Surrealismo. São Paulo, Edusp, 1997.

SARTRE, Jean-Paul. Uma idéia fundamental da fenomenologia de Husserl: a intencionalidade. In: Situações I. Trad. Cristina Prado. São Paulo: Cosac \& Naif, 2005, pp. 55-57. 